Revista de Filosofía

ISSN: 0034-8244

http://dx.doi.org/10.5209/RESF.64272

\title{
La verdad de la vida como antimodernismo. Análisis crítico de los primeros escritos de Heidegger (1909-1911) ${ }^{1}$
}

\author{
Francisco de Lara $^{2}$
}

Recibido: 06 de octubre de 2017 / Aceptado: 03 de mayo de 2018

Resumen. El presente artículo analiza los primeros escritos de Heidegger, en el contexto de sus orígenes católicos y antimodernos, a fin de mostrar en ellos una serie de aspectos característicos. La pretensión final consiste en poner de relieve los elementos valorativos y cosmovisionales que dirigen el pensamiento de Heidegger en sus inicios. De ese modo, se vuelve posible dejar planteada la pregunta de si dichos elementos no siguen jugando un papel decisivo, aunque menos visible ya, en toda la filosofía del primer Heidegger.

Palabras clave: Heidegger; catolicismo; ultramontanismo; antimodernismo; política.

\section{[en] The truth about life as antimodernism. A critical analysis of Heidegger's early writings (1909-1911)}

\begin{abstract}
This paper provides an analysis of Heidegger's early writings, within the context of his catholic and anti-modern background, in order to highlight some characteristic aspects. Its main purpose is to point out the worldview and value defining elements that guided his philosophical beginnings. Thus, the question may be posited about whether such elements still play a significant, albeit less explicit, role in the whole of the young Heidegger's philosophy.
\end{abstract}

Keywords: Heidegger; Catholicism; ultramontanism; antimodernism; politics.

Sumario: 1. Introducción; 1.1. Pretensión y alcance de este escrito; 1.2. La lucha cultural; 2. La verdad de la vida como catolicismo ultramontano; 3 . Ejemplaridad y carisma para sanar el alma del pueblo; 4. El tránsito de la teología a la ciencia estricta; 5. Conclusión; 6. Referencias bibliográficas.

Cómo citar: De Lara, F. (2019): "La verdad de la vida como antimodernismo. Análisis crítico de los primeros escritos de Heidegger (1909-1911)", en Revista de Filosofia 44 (1), 79-93.

\footnotetext{
1 El presente trabajo ha sido realizado en el marco del Proyecto Fondecyt Regular número 1191346 de Conicyt, Chile. La traducción de todos los textos de Heidegger citados es de mi autoría.

2 Facultad de Filosofía

Pontificia Universidad Católica de Chile

fdelara@uc.cl
} 


\section{Introducción}

\subsection{Pretensión y alcance de este escrito}

En lo que sigue analizaré con algo de detalle las primeras publicaciones de Heidegger, que coinciden con sus años como estudiante de Teología en Friburgo (1909-1911). Mi objetivo, sin embargo, no es única ni primariamente ilustrar ese periodo de formación del joven Heidegger, sino ante todo poner de relieve algunos elementos normativos que actúan ya entonces como guía de su pensamiento. Dicha puesta de relieve está motivada por una hipótesis de investigación sobre el pensamiento del primer Heidegger en su conjunto: a saber, que tales elementos normativos se mantendrían, con variaciones diversas, en los años posteriores y seguirían jugando un rol importante incluso en Ser y tiempo. Mi conjetura es que, aun cuando se lo despoje del contenido ultramontano con que se presenta al principio, el marco formal desde el que Heidegger juzga la vida, su propia época y el papel de la filosofía no desaparece de su pensamiento en los años siguientes, sino que se mantiene de un modo más subterráneo. Además, y en la medida en que dicho marco presenta un claro sesgo antimoderno y antiliberal, poseería una dimensión política que también me gustaría empezar a señalar en este escrito.

A fin de poner a prueba la hipótesis de lectura que aquí únicamente esbozo, sería necesario comparar el análisis que llevaré a cabo en este escrito con un examen similar de los siguientes aspectos del desarrollo intelectual de Heidegger: su abandono de los estudios de teología; su distanciamiento del catolicismo; el acercamiento al neokantismo, la fenomenología y el protestantismo; la nueva concepción de la ciencia y de la verdad que pone en marcha a partir de sus primeros cursos Friburgueses; la apropiación (en tono protestante) del cristianismo primitivo y el proyecto de una fenomenología de la vida fáctica; el ateísmo filosófico que empieza a declarar desde el curso del semestre de verano de 1922 (cf. GA 62, 283); la polémica con la teología como ciencia no originaria (1927) y las afirmaciones sobre el ideal fáctico-existentivo que guía los análisis de Ser y Tiempo. Por motivos obvios de espacio, en este escrito no podrá llevarse a cabo ese trabajo analítico y comparativo, por lo que el desarrollo de mi hipótesis y su posible confirmación o rectificación quedará pendiente de futuros escritos. En este primer acercamiento quisiera, por ende, limitarme únicamente a presentar dicha hipótesis a través del análisis de los primeros textos que Heidegger publica.

Para ello, empezaré por ilustrar brevemente el contexto de lucha cultural en el que se forma Heidegger. A continuación, comentaré varios de los primeros escritos publicados por él en diversos medios de difusión del catolicismo ultramontano, con el propósito de acentuar los aspectos que me parecen relevantes para aclarar el marco valorativo desde el que Heidegger se posiciona, así como sus implicaciones éticopolíticas.

\subsection{La lucha cultural}

Las primeras publicaciones de Heidegger se enmarcan en el contexto de la denominada "lucha cultural" (Kulturkampf). Se trata de la controversia que tuvo lugar a finales del s. XIX entre la Iglesia de Roma y el imperio alemán-prusiano, bajo el gobierno 
del canciller Bismarck. Así, mientras el segundo pugnaba por llevar a cabo una unificación de los estados alemanes bajo una idea centralista, y se apoyaba para ello en el Partido Nacional Liberal y su concepción laica del estado, diversos territorios de confesión católica se resistían y apelaban a la Iglesia romana y a su representante político nacional, el Partido Centrista de Alemania (Deutsche Zentrumspartei), para conservar su estatuto, sus costumbres y su fe. Esta disputa se declina en múltiples términos: protestantes contra católicos, Berlín contra Roma o prusianos contra ultramontanos. Se trataba, en definitiva, de la confrontación entre modernismo y antimodernismo, por expresarlo con los términos más usados entonces.

En sede filosófica, la querella se reflejaba en la defensa o bien el rechazo de la filosofía moderna y sus derivaciones contemporáneas, y en ocasiones se presentaba como una especie de gigantomaquia entre Aristóteles y Kant, aunque en realidad adoptara la forma, mucho más nimia y habitual, de disputas entre profesores neotomistas y sus colegas neokantianos. La misma Universidad de Friburgo no era ajena a esta batalla, sino que de hecho constituía uno de sus principales escenarios ${ }^{3}$. En ella enseñaban desde finales del siglo XIX neokantianos como Windelband, primero, y Rickert o Jonas Cohn después, junto con representantes de la filosofía católica como Carl Braig ${ }^{4}$, Artur Schneider ${ }^{5}$ o Heinrich Finke ${ }^{6}$. La trayectoria de Heidegger en esos años -que coinciden con su formación y sus primeros escritosestá marcada por este conflicto, y tomará justamente la forma de un tránsito desde el antimodernismo católico inicial, de tintes neoescolásticos, ultraconservadores y realistas, hacia el neokantismo y la fenomenología, cuyos principales representantes eran protestantes, liberales y continuadores de proyectos filosóficos de corte idealista. En lo que sigue me centraré en el primer momento y presentaré un análisis de las primeras publicaciones que Heidegger lleva a cabo durante los años en que todavía estudia Teología católica en la Universidad de Friburgo. Como veremos, este primer momento se caracteriza por una clara apologética católica antimoderna, si bien se apreciará al final, y coincidiendo con su congelación de los estudios de Teología, un cambio de tono en ella. De una apología inicial de tintes más retóricos y semi-literarios, Heidegger pasará a una apología de corte científico. En ambos casos, sin embargo, recurrirá a la misma división entre dos modos de vida: uno serio

3 Una clara exposición del contexto universitario en los años de estudio de Heidegger se encuentra ya en Casper (1980).

4 Sacerdote y teólogo católico "crítico del psicologismo, el subjetivismo y el protestantismo liberal" (HeideggerJahrbuch I, p. 29, nota 12). En su escrito "Mi camino en la fenomenología", el propio Heidegger se refiere al influjo de Braig en sus años de estudio (v. GA 14, pp. 81-82).

5 Especialista en Alberto Magno y en la influencia árabe y judía en la escolástica, fue profesor en Friburgo desde 1911, donde Heidegger toma ya dos cursos con él ese mismo año, aparte de ser después su director de tesis doctoral. En 1913, Schneider deja Friburgo para suceder en Estrasburgo a su maestro Clemens Baeumker, el también católico editor del Philosophisches Jahrbuch (de la Görres-Gesellschaft) en el que Heidegger publicó su trabajo de 1912 sobre el "Problema de la realidad en la filosofía actual" (GA 1, pp. 1-15). La concepción antimoderna, antimaterialista y antidemocrática de Schneider se deja ver a las claras en su escrito "Los fundamentos filosóficos de las cosmovisiones monistas" (v. Tilitzki 2002, p. 89). En la época nacionalsocialista fue miembro de la Nationalsozialistische Lehrerbund y de la Nationalsozialistische Volkswohlfahrt.

6 Historiador medievalista católico y posterior presidente de la Sociedad Görres (que fue fundada en 1876, en plena lucha cultural, para combatir el modernismo mediante el apoyo a trabajos académicos de profesores y estudiantes católicos). Dicha Sociedad becó a Heidegger en varios momentos de su carrera (v. Ott 1986, 2004 y 2005). El apoyo de Finke para que Heidegger sucediera a Schneider en la cátedra de filosofía cristiana no fue suficiente, algo que a la vez contribuyó a un acercamiento más decidido de Heidegger a Rickert y a su sucesor Husserl, profesor en Friburgo desde 1916. 
y verdadero, representado por su postura, y uno frívolo y falso, representado por la postura contraria.

\section{La verdad de la vida como catolicismo ultramontano}

En efecto, Heidegger inició su camino como pensador en las filas del antimodernismo, por lo que sus primeros escritos presentan un tono decidida y combativamente católico. El primer texto que publica se titula "Allerseelenstimmungen" y vio la luz en las dos primeras páginas del diario ultramontano de Messkirch, el Heuberger Volksblatt, el 5 de noviembre de 1909, cuando Heidegger tenía 20 años recién cumplidos y se encontraba iniciando su primer semestre de estudios universitarios ${ }^{7}$. Dicho texto relata la conversión de un joven ateo citadino en la mañana del día de Todos los Santos, impresionado por el Dies irae que escucha en la misa catedralicia y le revela la mentira de su vida pasada. El modo como Heidegger describe las primeras horas de la mañana del 1 de noviembre son características de la prosa antimodernista. Las amplias calles de la gran ciudad son "grises y turbias y húmedas y frías" (HeideggerJahrbuch I, p. 18), sus ciudadanos no escuchan las campanas que llaman a misa en esa mañana de luto (Trauer), "odian su sonido, quieren el placer, buscan el sol y deambulan en la noche; en la oscura y tormentosa noche" (ibíd.). La muerte llega a todo y a todos, recuerda Heidegger, también a esos hombres "buscadores del placer" e incapaces de "seriedad" (Ernst). Dicha seriedad precisa una fuerza de la que ellos ya carecen, pues "los hombres de hoy son débiles, su yo soberano se ha apartado de toda autodisciplina (Selbstzucht). Con pesadas cadenas -aunque ellos ya no escuchan el sonido-arrastran sus cuerpos cansados y sobreexcitados a través de la existencia (Dasein)" (ibíd.). Este débil modo de vida se cree libre, pero estaría en realidad esclavizado por las cadenas de esa falta de seriedad y de verdad. Según Heidegger, los liberales modernos "no hallan los puentes que conducen a la tierra de la verdad, no quieren hallarlos" (ibid.).

Ya en este escrito -cuyo tono recuerda inconfundiblemente al Zaratustra y contiene una referencia a la "bestia rubia" de La genealogía de la moral-Heidegger considera a Nietzsche como uno de los principales enemigos a combatir, pues su voz tentadora habla de romper las tablas y dar rienda suelta a ese placer que "quiere profunda, profunda eternidad". El joven citadino, que había llegado a la misa movido por sus impulsos habituales -curiosidad y búsqueda de nuevos estímulosse ve golpeado por la verdad que el Dies irae le revela. Aunque sus antiguos ídolos lo tientan, oye una voz suave desde lo más profundo del corazón que le manifiesta la verdad sobre su vida, pues le revela el principio que le había guiado hasta entonces: "Era el espíritu de la mentira, que se niega a sí mismo. Has hecho oficios de esclavo, indignos oficios de esclavo" (idem, pp. 20-21). Derrumbado y vencido, el joven escucha el "Huic ergo parce Deus" de la Lacrimosa; y esas palabras que piden a Dios misericordia con él, "hombre culpable", le suenan como "ruegos de niño".

Heidegger inició sus estudios de Teología en el semestre de invierno de 1909, es decir, un par de semanas antes de publicar ese primer texto. Un buen comentario del mismo se encuentra en Fischer (2013), pp. 52-54. V. también, sobre este escrito y los que siguen, Wolfe (2013), pp. 14-ss.

8 Heidegger cita el Nachtwandlerlied del Zaratustra, que Mahler había musicalizado unos años antes, en su Tercera sinfonía de 1902.

9 Dentro del Dies Irae -Sequentia o himno litúrgico dedicado al día del Juicio final- la parte conocida como 
Ante esa revelación, "los labios descoloridos del joven susurran "misericordia" y él se arrodilla forzosamente" (ídem, p. 21). El joven deja atrás la mentira de su vida pasada y se convierte a la verdad del catolicismo.

Esta contraposición entre una verdad y una mentira de la vida es, a mi entender, uno de esos elementos característicos del pensamiento temprano de Heidegger a los que me referí al principio y que me gustaría poner de relieve. A ella le dedica también el segundo de sus escritos, publicado en marzo de 1910 en Der Akademiker -revista mensual de la asociación de académicos católicos ${ }^{10}-\mathrm{y}$ titulado justamente "Per mortem ad vitam. Reflexiones sobre Mentira de la vida y verdad de la vida de Jörgensen". En la obra que Heidegger comenta, el escritor danés Johannes Jörgensen describe su camino desde el ateísmo y el darwinismo hasta su conversión al catolicismo en 1896, impresionado ante todo por San Francisco de Asís, de quien Jörgensen sería un importante biógrafo. Así pues, en este segundo escrito Heidegger vuelve a tratar de la conversión, entendida como paso de una vida falsa a una verdadera. El texto se inicia repitiendo las críticas al estilo de vida de escritores y pensadores de la época, como Wilde, Ibsen o, una vez más, Nietzsche, cuyo culto a la personalidad y a lo subjetivo y vivencial era condenado por los antimodernistas. Se trataría de una forma falsa de vida y al respecto nos deja Heidegger la siguiente afirmación que él presenta, literalmente, como una ley biológica fundamental: "La verdad debe conducir naturaliter a la buenaventura (Glück), la mentira al ocaso (Untergang) [...] Si te apartas de la verdad, ella te castigará por tu transgresión" (GA 16, p. 5). Y continúa:
¿Acaso las grandes "personalidades" encontraron la buenaventura? No; [solo] desesperación y muerte. Mira [...] cómo se apartaron y acabaron apuntándose con un revólver en la frente. Por consiguiente, no tenían la verdad. Por consiguiente, el individualismo es la forma falsa de vida (falsche Lebensform). Destierra, pues, la voluntad de la carne, la doctrina del mundo, el paganismo (ibíd.).

Más allá de los problemas de lógica elemental que presentan la argumentación y las conclusiones que Heidegger extrae de estos ejemplos, me interesa simplemente poner de relieve que en estos primeros escritos habla un clásico ejemplar de fanático ultramontano y antimodernista. En la línea de su gran amigo de esos años, Ernst Laslowski, que prefería ser un mediocre profesor católico antes que un eminente científico protestante o darwinista ${ }^{11}$, Heidegger antepone a un literato mediocre como Jörgensen a escritores de la talla de Ibsen, Gorky, Wilde, Verlaine o Nietzsche. Pues, a diferencia de ellos, Jörgensen se atrevió a dar un paso que la mayoría consideraría "insípido y asqueroso" (ibid.), la conversión al cristianismo, y además lo hizo movido

Lacrimosa refiere a los últimos versos: "Día de lágrimas será aquel día/en que resucitará del polvo/para el juicio el hombre culpable./A ése, pues, perdónalo, oh Dios./Señor de piedad, Jesús,/concédeles el descanso./Amén." Heidegger organiza todo su escrito siguiendo los versos del Dies irae y el efecto que éstos van provocando en el ánimo (las Stimmungen) del joven.

10 Sobre Der Akademiker, v. Ott (1988), pp. 62-63.

11 V. la carta de Laslowski a Heidegger del 2 de diciembre de 1911, en la que afirma que "prefiero ser Kaplan, desconocido, antes que Haeckel o Harnack, que tanto han hecho por la ciencia", es decir, antes un católico insignificante que un darwinista como el zoólogo Ernst Haeckel -blanco especial de las críticas antimodernistas al que el propio Heidegger criticará (v. Büchin/Denker 2005, p. 127)- o un teólogo protestante como Leopold von Harnack. Del mismo modo, Laslowski prefiere "ser Finke en Friburgo que [Leopold von] Ranke en Berlín, si aún viviera" (Heidegger-Jahrbuch I, p. 31). 
por lo que Heidegger considera, como ya hemos visto, un valor fundamental en los tiempos frívolos que le tocó vivir: "la seriedad (Ernst) profunda y amarga" (ibíd.). Como vemos, aparece aquí de nuevo este término clave que ya se encontraba en el primer escrito: la vida verdadera se mide por la capacidad de soportar una sacrificada y profunda seriedad.

Los inicios de Jörgensen estuvieron marcados por el influjo de las corrientes modernistas, así como de Nietzsche y Zola, entre los intelectuales daneses. De uno de ellos, el naturalista ateo y darwinista Hans Peter Jacobsen, que contrajo la tuberculosis y luchó contra ella toda su vida, Heidegger se atreve a decir -sin la más mínima compasión cristiana- algo muy similar a lo afirmado en su escrito de Todos los Santos sobre los modernos citadinos: a saber, que, "siendo demasiado débil para vivir y no estando enfermo de muerte, se arrastró por su miserable existencia (Dasein)" (ibíd.). Heidegger cita al propio Jacobsen expresando su fascinación por lo salvaje, por la naturaleza indómita y la pasión insaciable de los hombres del Renacimiento, para realizar a continuación un comentario digno de un censor enfurecido: "El más puro entusiasmo por César Borgia propio de un Nietzsche. [Estos modernistas] esparcían incienso a los ídolos de la atrocidad y el pecado. En sus altares estaban el becerro de oro, la fama y la Venus de Babilonia" (ídem, p. 4). La sensualidad, el gusto por la naturaleza, lo "bestial" e instintivo es denostado por este joven moralista como parte de la frivolidad mundana que desconoce la seriedad de la existencia.

Sin detenerme a exponer en detalle un escrito de calidad más que discutible, lo que me importa señalar es que este segundo texto no solo es extremadamente cercano al primero en forma y fondo, sino que además repite y refuerza varios de los símbolos binarios que ya encontramos en aquél: salud/enfermedad, vida/muerte, día/noche, libertad/esclavitud, ruido/silencio, fuerza/debilidad y seriedad/dispersión.

\section{Ejemplaridad y carisma para sanar el alma del pueblo}

En esta misma línea de enjuiciamiento binario se expresa el texto -también de 1910 que Heidegger escribió en ocasión de la inauguración de un monumento dedicado a Abraham de Santa Clara, convertido entonces en símbolo del antimodernismo ${ }^{12}$. Allí vuelve a referirse al "sentido moderno de la vida, dirigido a estímulos momentáneos que se van alternando incesantemente" como algo que apunta "a una decadencia, a una lamentable disminución de la salud y del valor trascendente de la vida" (GA 13, p. 3). Por ello, Heidegger considera que

modelos como Abraham de Santa Clara deben conservarse entre nosotros y seguir actuando silenciosamente en el alma del pueblo. Que sus escritos sean moneda todavía más corriente, y que su espíritu [...] se vuelva un poderoso fermento para mantener sana $\mathrm{y}$, donde sea preciso, curar una y otra vez el alma del pueblo (ibíd.).

12 El texto "Abraham a Sankta Clara" solía considerarse el primero publicado por Heidegger (así lo hace incluso Hermann Heidegger, editor de GA 13), pero apareció el 27 de agosto de 1910 en el Allgemeine Rundschau, un "Semanario de política y cultura" fundado en 1904. Desde su fundación, dicho semanario se declaraba al servicio de la Iglesia católica y el Partido Centrista Alemán, órgano político de ese mismo catolicismo al que se debía también el ya mencionado Heuberger Volksblatt. 
Como puede apreciarse, la salud o enfermedad es para este joven pensador un fenómeno anímico, que depende de los alimentos espirituales recibidos y de la atmósfera respirada, pero que además requiere de ejemplos, de modelos carismáticos. El mantenimiento de un cierto tipo de vida como la que Heidegger reclama - una vida que se atreve a luchar contra la decadencia y la enfermedad- necesita individuos ejemplares. Para Heidegger, dichos ejemplos de vida deben ejercer su salvador efecto de un modo silencioso, una vez más ${ }^{13}$. Además, esa lucha entre verdad y mentira, salud y enfermedad, no se libraría sólo en cada alma individual, sino también en el alma del pueblo, como evidencia este escrito por primera vez. Así pues, en la encrucijada entre una forma de vida falsa y una verdadera subyace, en última instancia, también un claro programa político. No solo está en juego la salvación de cada cual, sino la del pueblo todo, y esa salvación se encuentra en la verdad del catolicismo antimoderno y ultramontano. Se hace patente, de este modo, que el marco valorativo binario con el que Heidegger divide la existencia entera conlleva posicionamientos políticos de corte ultraconservador. Los pares normativos con los que Heidegger se posiciona y define, sin matiz alguno, las posiciones en pugna como otros tantos modos de vida tienen como trasfondo una postura política. Dichos pares juzgan sobre el modo como debería articularse la vida en común, sobre lo que sería sano para la comunidad - presentada, además, ya en este escrito con una categoría política tan poco neutra como "pueblo"-. El pueblo, para mantenerse sano, debería seguir las consignas de la Iglesia católica y sus representantes ejemplares, tanto pasados como presentes. Esto implica, a un tiempo, repudiar sin matices todo lo que provenga del lado liberal.

Unos pocos meses antes, en mayo de este mismo 1910, Heidegger había reseñado -también en Der Akademiker- el libro de Friedrich W. Förster sobre Autoridad y libertad, dedicado justamente a reflexionar "Sobre el problema cultural de la Iglesia" y a defender la autoridad de la misma y la compatibilidad entre dicha autoridad y la libertad ${ }^{14}$. Se trata de un tema crucial, en el que se juega incluso la cuestión de la libertad de investigación y cátedra. En efecto, el catolicismo de entonces se veía especialmente confrontado a la pregunta sobre la compatibilidad entre libertad de investigación y autoridad doctrinal de la Iglesia. Se trataba de uno de los puntos que los liberales más le reprochaban a los pensadores y científicos católicos del momento; un reproche que se recrudecerá con el motu proprio del 1 de septiembre de este mismo 1910 al que me referiré más adelante.

Heidegger no duda en plantear el asunto a partir de una descalificación de las corrientes de pensamiento en boga como incapaces de una verdad que posee un profundo significado religioso-moral. En ese sentido, pone al mismo nivel "el obstinado fanatismo de la realidad efectiva (Wirklichkeit)" que sería propio del "ordenamiento de la vida naturalista-socialista" 15 y la "filosofía de la inmanencia", esto es, de la conciencia ${ }^{16}$. Ambas tendencias tendrían en común su "autonomismo",

13 Esta apelación constante a lo callado y silencioso resulta como mínimo sorprendente, por no decir retórico, si se considera el ajetreo y el ruido combativo con que los integristas católicos como Heidegger combatían el modernismo en los diversos medios de difusión afines a su causa.

14 Sobre este texto y el próximo que comentaré, puede verse Schmidt (2005), pp. 47-48.

15 En esta identificación entre naturalismo y socialismo se aprecia, una vez más, el trasfondo político de las valoraciones filosóficas de Heidegger.

16 En su primer escrito de corte más filosófico - el ya mencionado "El Problema de la realidad en la filosofía actual" que publica en 1912 en el Philosophisches Jahrbuch de la Sociedad Görres-, Heidegger aclara que esta 
es decir, la convicción de poder encontrar la verdad por medios únicamente humanos y más allá de toda autoridad doctrinal, y en eso consistiría precisamente su error. Tal pretensión manifestaría a las claras el subjetivismo individualista, el yo hipertrofiado, de los modernos. Para Heidegger, como para Förster, las verdades concernientes a "los problemas más profundos de la vida religioso-moral" no pueden resolverse mediante "el moderno individualismo" (GA 16, p. 7). Para dar con "las verdades fundamentales de la vida" serían necesarias condiciones que nada tienen que ver con construcciones científicas a priori, sino que reclaman la conjunción de una "experiencia vital rica y profunda" con "la libertad espiritual respecto del mundo de los instintos" (ibíd.). Así pues, no se llegaría a las verdades fundamentales a través de métodos científicos, sino una vez más mediante cualidades de índole personal y ética.

Además, dichas cualidades no se darían a menudo de forma conjunta, sino que serían propias de personas excepcionales. Heidegger -que, al más puro estilo neoescolátisco, alaba el método "inductivo" de Förster- pretende refutar el individualismo en ética con el argumento de que "la mayoría de los seres humanos, si tienen que arreglárselas por ellos mismos, no encuentran la verdad, no la quieren alcanzar, sino que por el contrario la crucifican". El culto a la personalidad, tan propio de los modernistas, solo tendría para este Heidegger un desarrollo adecuado "si se mantiene en el más íntimo contacto con la fuente más rica y profunda de autoridad religioso-moral” (ibid.), esto es, con la católica.

La tarea de dicha Iglesia no pasaría por adaptarse a los tiempos y sus tendencias, sino todo lo contrario: ella debe combatir enérgicamente "las influencias del modernismo" como el camino para "mantenerse fiel a su eterno tesoro de verdad" (ibíd.). Heidegger considera que el libro reseñado alegrará y reafirmará, por ello,

a quien nunca puso el pie en caminos errados y no se dejó deslumbrar por la apariencia engañosa del espíritu moderno, a quien puede atreverse a ir por la vida en el verdadero, profundo y fundado abandono de sí (Entselbstung) en la resplandeciente luz de la verdad $(\text { GA } 16, \text { p. } 8)^{17}$.

Situado en las antípodas del autonomismo individualista, Heidegger aboga por el abandono y la entrega a una autoridad superior que encarna y hace partícipe de la verdad -y la libertad- de la vida. De ahí que culmine su reseña con la frase del ultramontano Joseph Görres, para quien bastaría siempre con cavar más hondamente para topar con suelo católico (cfr. ibíd.). En efecto, para este Heidegger la doctrina más verdadera, profunda e invariable es siempre la defendida por la Iglesia romana.

Cabe mencionar que, aunque Heidegger lo lea desde esa óptica, Förster no pretendía ofrecer un fundamento del ultramontanismo, sino que abogaba por reconocer el valor ético-educativo de la Iglesia entendida de un modo universalista. Como él mismo aclara en un escrito de 1911 en el que discute la recepción de su libro, Förster aboga por una institución que aúne "la verdad de la antigua Iglesia con las necesidades de la conciencia protestante y del pensamiento científico" (Förster 1911, p. 273) y que, de ese modo, proporcione una verdadera cultura y a la vez termine

denominación de "inmanentismo" refiere a filosofías subjetivas como la de Schuppe (cf. GA 1, p. 5).

17 V. el acertado comentario de este pasaje, a la luz de sus fuentes bíblicas, en Wolfe (2014), p. 13. 
con el conflicto religioso-político ${ }^{18}$. De hecho, no duda en elogiar la personalidad de Lutero ni le tiembla la mano al afirmar que "las últimas encíclicas papales" de Pío X contienen "expresiones tan poco históricas como poco cristianas" (ibíd.). Por todo ello, si bien Heidegger encuentra en Förster munición para su lucha antimoderna, y valora que haya sido capaz de la "valentía" necesaria para reconocer la verdad del catolicismo en esos tiempos, la reseña termina con una versión de la frase que San Agustín dedicaba a los filósofos paganos virtuosos: "grandis passus [sed] extra viam" (GA 16, p. 8).

Como puede apreciarse, el modo como Heidegger defiende la autoridad de la Iglesia católica en este escrito se apoya en un punto de partida exactamente opuesto al de Descartes o la tradición ilustrada y científica moderna. Lejos de la convicción según la cual todo ser humano cuenta con las capacidades intelectuales necesarias para llegar a conocer todo lo humanamente posible, Heidegger considera que muy pocos reúnen los requisitos indispensables para encontrar la verdad. Eso es así porque Heidegger identifica dicha verdad con un conocimiento "profundo" -el adjetivo aparece hasta la saciedad en este breve escrito- sobre la vida. Heidegger está pensando en una verdad revelada y metafísica como la verdad por antonomasia, y no en una verdad que el uso de las capacidades intelectuales comunes nos permitiera descubrir. Para vivir en aquella verdad hacen falta cualidades de otra índole, a saber, de carácter personal-existencial ${ }^{19}$. Ese tipo de cualidades, sin embargo, están lejos de ser comunes a todos los seres humanos. Según Heidegger, la mayoría no solo no está capacitada para encontrar autónomamente la verdad, sino que de hecho no la busca en absoluto e incluso se mueve en la dirección de negarla y destruirla. La masa -entendida aquí como suma de individuos egoístamente dispuestos-no solamente es incapaz de verdad, sino que de hecho es una amenaza para ella. De ahí la necesidad de una guía autorizada, en forma de ejemplo o liderazgo jerárquicamente superior, que revele y mantenga vivas las verdades espirituales que deberían guiar el orden político y social. Así pues, la necesidad de tal instancia jerárquica no está única ni principalmente basada en motivos de carácter epistemológico, insisto, sino ante todo de carácter existencial. No es que esa verdad resulte difícil de hallar y precise de un trabajo metódico complejo y poco habitual, en el que uno debe aprender de quienes poseen mayor experiencia, sino que requiere una valentía y seriedad de la que pocos pueden preciarse en unos tiempos de esclavitud materialista y bajeza espiritual.

Heidegger legitima la autoridad de esa verdad preciada apelando al mayor grado de libertad de espíritu - esto es, de superación de las tendencias más básicas

18 En su librito Das Kulturproblem der Kirche de 1920, vuelve a dejar claras sus intenciones de combatir el materialismo (tanto científico como social) por considerarlo un signo del "colapso de Alemania" (1920, VI). Förster califica a los alemanes como "guardianes de los bienes invisibles", espirituales, a los que "solo les estaba permitido hacer política en la más estrecha conexión con ese designio (Beruf); debíamos ser servidores del Cristo político" (ídem, p. VII). Por ese motivo, considera que la Iglesia católica tiene una importante misión, si bien pone en cuestión que dicha Iglesia sea consciente de ello y no esté movida más bien por el afán de poder material. Förster reconoce las oposiciones en las que se divide la Alemania de la época, pero su pretensión no es ponerse de un lado y terminar con el otro, sino una convivencia y complementación mutua.

19 Conviene mantener a la vista y rastrear en escritos posteriores este elemento "irracionalista" de Heidegger -por decirlo con Lukács (Lukács 1962, p. 420)-, pues incluso su idea de una ciencia originaria o de una ontología fundamental parecen depender en última instancia de elementos existentivos, éticos y decisionales. Al respecto, convendrá tener presentes las críticas que Habermas sobre las condiciones de legitimidad y validez del discurso filosófico heideggeriano, en cuanto pretendido discurso racional que, sin embargo, rompe con toda condición de validación intersubjetiva y degenera en un "criptonormativismo" (sobre estos puntos v. Habermas 1989a, especialmente p. 174-184, Habermas 1989b, pp. 15-ss. y Habermas 1987, p. 475, nota al pie 87). 
y animales- que ella encarna, por lo que libertad y autoridad no se ven aquí contrapuestas, sino que de hecho van de la mano. La autoridad de la Iglesia es el único camino a la verdad $\mathrm{y}$, por ende, a la libertad. Una consecuencia de ello que Heidegger no explicita aquí -pero sí en otros lugares ${ }^{20}$ - es que sería impensable una libertad de cátedra e investigación que se opusiera a los dogmas eclesiales. Si solo la Iglesia es capaz de revelar la verdad, y por ende de permitirnos una auténtica y profunda libertad, supondría un contrasentido pretender encontrar verdades que contradigan sus dogmas. Está clara la consecuencia académico-científica de esta convicción: la ciencia moderna no podrá jamás contradecir las verdades que solo la Iglesia católica revela, a lo sumo podrá confirmarlas. No menos claras aparecen las consecuencias políticas: si solo la Iglesia tiene acceso a las verdades que deberían guiarnos individual y colectivamente, la política debería estar, o bien directamente en sus manos, o bien indirectamente en las del partido que la represente. No es por ende la verdad (representada por la Iglesia) la que debe adaptarse a los tiempos, ni será por acuerdos y concesiones a los tiempos como se llegue a tal verdad. Ni la ciencia, ni la democracia, ni la mayoría tienen aquí nada que opinar: solo mediante la Iglesia es posible alcanzar la verdad que nos libera y sana.

\section{El tránsito de la teología a la ciencia estricta}

A la luz de los ejemplos anteriores, queda más que clara la posición radicalmente papista de Heidegger en los escritos que publica entre noviembre de 1909 y agosto de 1910, durante sus dos primeros semestres de estudiante de Teología. Poco después, sin embargo, vio la luz un nuevo documento papal que supondría un cierto cambio en el tono apologético de Heidegger y lo llevaría, finalmente, al abandono de dicha carrera. Me refiero al ya mencionado motu proprio de Pío X publicado el 1 de septiembre de 1910 bajo el título de Sacrorum antistitum. En él se exacerbaban las medidas para combatir el modernismo, pues se imponía un 'juramento antimodernista' a 'todo el clero, los pastores, confesores, predicadores, superiores religiosos y profesores de filosofía y teología en seminarios" ${ }^{21}$. El primer párrafo del mismo confiere obligatoriedad a los textos doctrinales "dirigidos contra los errores de estos tiempos", esto es, a las anteriores encíclicas y listas de errores promulgadas por Pío IX, León XIII y el propio Pío $\mathrm{X}^{22}$. Acto seguido, obliga a profesar una serie de creencias que revelan tanto en su contenido como en su forma un inconfundible sello neotomista.

El juramento, sin embargo, no obligaba sólo en términos de doctrina, sino también en lo relativo a la metodología de investigación. En él se prohíbe de nuevo cualquier posibilidad de evolución en el sentido de los dogmas y cualquier estudio que pretenda poner en cuestión la visión defendida por la Iglesia sobre los orígenes de la religión cristiana. En una palabra, se niega la posibilidad de una investigación histórica, basada en los avances de la filología y las reflexiones sobre las ciencias

20 Cf. los textos con los que Heidegger toma parte en la "guerra periodística de Messkirch", recogidos en Büchin/ Denker (2005), pp. 62-ss.

21 Subrayado mío. El documento puede consultarse en línea: http://w2.vatican.va/content/pius-x/la/motu_proprio/ documents/hf_p-x_motu-proprio_19100901_sacrorum-antistitum.html

22 En especial sus encíclicas Pascendi y Lamentabili, que son explícitamente mencionadas en el texto del juramento como textos a los que hay que someterse "con la debida reverencia". 
históricas. En la misma línea, el juramento prohíbe basarse exclusivamente en un método de crítica textual y también juzgar libremente en el estudio de materias histórico-teológicas. Por último, se rechaza que un cristiano pueda sostener algo en cuanto investigador y otra cosa como creyente, con lo que de facto se prohíbe a cualquier investigador creyente afirmar algo que pudiera considerarse divergente de los dogmas y se rechaza, de esta forma, toda posibilidad de distinguir entre uso público y privado de la razón.

Los teólogos de la Universidad de Friburgo acataron el juramento, algo que fue percibido en dicha universidad como una restricción de su libertad de investigación y cátedra. El senado universitario se negó incluso en un primer momento a reconocer a los profesores de la Facultad de Teología como verdaderos investigadores dignos de ser parte de la universidad. El conflicto escaló hasta el punto que tuvo que intervenir el gobierno de Karlsruhe para que se llegara a un acuerdo ${ }^{23}$. Dicho conflicto coincide con el momento en el que Heidegger interrumpe sus estudios de Teología. Concretamente, a mediados de febrero de 1911 fue enviado a descansar a Messkirch por una dolencia cardíaca, con el permiso de congelar los estudios también en el semestre siguiente ${ }^{24}$. Los escritos -así como las conferencias sobre el modernismo, Nietzsche o el darwinismo- que Heidegger escribe y dicta en su ciudad natal durante este periodo ${ }^{25}$ muestran su primera toma de posición respecto al juramento, esto es, sobre la posibilidad de una auténtica investigación científica en el seno de la postura oficial de la Iglesia del momento. De hecho, Heidegger defiende en un principio dicha posibilidad, como veremos a continuación, y lo hace justamente con un tono mucho más marcadamente científico-académico que en los escritos que hemos considerado hasta ahora. El apologeta semi-literario de los primeros textos deja paso a un apologista científico-académico. La seriedad que es propia de la vida verdadera toma en lo que sigue la forma de cientificidad rigurosa.

Quisiera leer en esta línea su texto con instrucciones "Sobre orientación filosófica para académicos", publicado asimismo en la revista Der Akademiker en marzo de 1911. Este texto empieza ya con una declaración de principios al afirmar que la filosofía es "en verdad un espejo de lo eterno" (GA 16, p. 11). En la situación actual, sin embargo, dicho espejo ya solo reflejaría "opiniones subjetivas, estados de ánimo y deseos personales" (ibid.), en consonancia con la predilección por las "vivencias" y los "sentimientos" tan propia del subjetivismo y el individualismo modernos. Heidegger, que en el escrito anteriormente comentado mostraba rasgos claramente antiintelectualistas -al valorar las cualidades morales y no las intelectuales a la hora de encontrar la verdad- utiliza en este justamente el reproche de antiintelectualismo para denostar a las filosofías de corte vitalista e irracionalista. Dichas filosofías serían incapaces del rigor de la lógica; su afán de liberarse de los límites que ella impone no demostraría sino su debilidad a la hora de controlar sus bajos impulsos y ponerse al servicio de una verdad eterna. En la pretensión de algunos pensadores como Nietzsche -a quien no cita, pero tiene claramente a la vista- de llevar el pensamiento más allá de los límites de una cierta lógica, Heidegger encuentra, una vez más, un trasfondo ético-vital. La lógica, con su rigor y frialdad, pasa ahora a simbolizar un tipo de vida valiente, entregada a algo distinto de nosotros mismos y dotado de un

\footnotetext{
V. al respecto Wolfe, 2014, p. 15.

Sobre esta “crisis" puede verse Xolocotzi (2009), 37-40. V. también Büchin/Denker, 2005, p. 124 y nota 7.

V. Büchin/Denker, 2005, p. 129-ss.
} 
valor más elevado, eterno ${ }^{26}$. Tal y como será también característico de sus análisis posteriores, Heidegger considera ya aquí la ciencia -y en especial la ciencia estrictadesde una perspectiva existencial. Se trata de una forma de vida, de un modo de relación con uno mismo y el mundo. En concreto, en la cientificidad rigurosa y no subjetivista tendría lugar para este Heidegger una vida capaz de superar el egoísmo y el hedonismo, de autoentregarse y sacrificarse por un bien superior. Para Heidegger, tanto "el pensamiento lógico estricto, que se cierra herméticamente a toda influencia afectiva proveniente del ánimo (Gemüt)" como, en general, "todo trabajo científico verdaderamente (wahrhaft) libre de presupuestos" conlleva "un cierto fondo de fuerza ética, el arte del auto-recogimiento y el auto-desprendimiento (Selbsterraffung und Selbstentäusserung)" (ibid.). Heidegger se acerca aquí de nuevo a Nietzsche, al tratar la ciencia desde el punto de vista de su valor para la vida, si bien con un juicio diametralmente opuesto al de éste. La vida más valiente y sana sería nada menos que la dedicada a verdades inamovibles.

Las orientaciones que Heidegger pretende ofrecer a los académicos en este escrito van en la dirección de indicarles el peligro de la dispersión en la que pueden caer ellos mismos y sus educandos si pretenden enseñar todo lo que la moda considera importante. Se desliza de esa manera una nueva crítica al ajetreo de los modernos, que no conduce sino a que el estudiante se pierda a sí mismo. Con ello, afirma, "se crea un estado ilógico, insano" (ídem, p. 12, subrayado mío). Para combatirlo, Heidegger da por supuesta la necesidad de una formación completa en apologética, y también considera valiosas las conferencias que tratan la religión científicamente, dado que en ellas "las verdades eternas del cristianismo se presentan con su eterna grandeza ante el alma de los estudiantes católicos, despiertan su entusiasmo, les recuerdan "lo que tenemos"' (ibíd.). Heidegger, no obstante, subraya la necesidad de una dedicación en primera persona, en la que cada cual se hace responsable del potencial que se encuentra en esas verdades. En la línea de esta acentuación de la cientificidad, Heidegger pone por primera vez el foco en un cierto "egoísmo" bien entendido que sería propio de la formación, pues en ella cada cual debe privilegiar la pretensión de conocer y trabajar en primera persona por encima de la mera repetición pasiva. La entrega a las verdades eternas no implica la docilidad del que repite indiferentemente. Lejos de toda forma fácil y cómoda de vida, dicha entrega requiere la mayor valentía e implicación personal.

La postura de fondo de Heidegger no ha cambiado aún en este momento: sigue creyendo firmemente en los dogmas católicos e incluso pretende defender la validez del juramento antimodernista. Lo que ha cambiado es la forma académico-científica que adopta esa defensa y la valoración de la lógica y las ciencias estrictas que se inicia en este momento. Esa misma línea de apología científico-académica la encontraremos en los artículos que publica en el Heuberger Volksblatt a partir de abril de 1911, en los que defiende el 'juramento antimodernista' contra los filósofos del diario liberal Badischer Grenzbote ${ }^{27}$. Sin embargo, en esta nueva estrategia apologética se encuentra ya un germen que podría dar luces del motivo por el que Heidegger se irá apartando de su posición de partida. La lógica, las ciencias estrictas

26 Schaber ha mostrado adecuadamente esta función de la lógica como "ciencia fundamental de la apologética" en este periodo del pensamiento de Heidegger. V. Schaber (2007), pp. 99-ss.

27 Esta polémica se da en el contexto de la llamada "guerra periodística de Messkirch", ya mencionada. Los textos de Heidegger se encuentran en Büchin/Denker (2005), pp. 62-ss. Sobre la polémica entre estos dos diarios, órganos del partido liberal y del partido centrista, respectivamente, puede verse Vonberg (2003). 
y el trabajo filosófico serio se le irán revelando como incompatibles con imposiciones doctrinales que pretenden decidir incluso sobre el método de investigación. Esto le llevará a abandonar los estudios de Teología, primero, su apego a la escolástica, seguidamente, y el "sistema" del catolicismo, por último. Se trata de un camino que durará unos años y tomará distintas formas hasta llegar al Heidegger que conocemos como un filósofo original, a partir de los primeros cursos friburgueses. Sin embargo, me parece plausible conjeturar que esas indudables transformaciones en el modo de entender el trabajo intelectual y la filosofía no acabarán con las convicciones más profundas de Heidegger sobre la verdad, la vida y la sociedad. El alejamiento paulatino del "sistema del catolicismo" bien podría estarse llevando a cabo en nombre de los mismos valores que la fe y la forma de vida católica representaban en estos primeros años. De ser así, cambiaría el modelo concreto de existencia y sociedad que Heidegger considera superior, pero no el marco valorativo desde el que todo ello se juzga.

\section{Conclusión}

Seríamos injustos si pretendiéramos juzgar a un joven estudiante de Teología católica con el baremo de un pensador maduro como el que llegó a ser Heidegger. El momento en que publica estos textos permite entender tanto su defensa apasionada de la Iglesia católica como su falta de madurez argumentativa. Lo que me interesaba señalar, sin embargo, es que su postura teológico-política dista mucho de ser moderada. Representa más bien un extremo fanático que tiende a reducir todos los matices y presentar la vida individual y colectiva ("pueblo") como una lucha a muerte entre dos bloques irreconciliables. Esa tendencia al radicalismo y el extremismo, esa identificación con los sectores más ultraconservadores y combativos, es un rasgo característico del Heidegger de estos escritos que no puede achacarse sin más a su falta de madurez como pensador o a la elección de una vida religiosa.

Aunque podrían añadirse no pocos ejemplos más para detallar la posición filosófico-política de Heidegger en sus años de estudiante de Teología, el análisis realizado en las páginas anteriores basta para perfilar la hipótesis que me proponía esbozar en este escrito. A tal efecto, me permito presentar a modo de conclusión los cuatro aspectos que he querido subrayar. El primero es que Heidegger se posiciona en la lucha contra el modernismo mediante el establecimiento de un marco valorativo binario en el que el enemigo liberal representa todos los valores negativos y el catolicismo conservador todos los valores positivos. Destaco de ello la tendencia a una cosmovisión dual cargada de valoraciones y en la que, sin matiz alguno, una parte es presentada como decadencia y la otra como salud vital. Lo segundo a destacar son los valores mismos en oposición, entre los que se cuentan varios que, con variaciones en ocasiones incluso menores, pueden encontrarse en los años siguientes. Me refiero a elementos como vida/muerte, libertad/esclavitud, ruido/silencio, fuerza/debilidad, seriedad/aligeramiento y concentración/dispersión. De este modo, se vuelve plausible la hipótesis acerca de una posible continuidad subterránea en el pensamiento de Heidegger desde 1909 hasta 1927, por lo menos, y además en aspectos que no son de menor envergadura, sino que concernirían al fondo del pensamiento heideggeriano. Tal continuidad se apreciaría especialmente en la ya mencionada distinción entre una mentira y una verdad de la vida, que parece destacarse como un motivo recurrente en 
el pensamiento del primer Heidegger bajo fórmulas como vida caída/vida existente (en los primeros cursos de Friburgo) o propiedad/impropiedad (en Ser y tiempo). Lo tercero que quisiera señalar es que Heidegger lleva a cabo esa división en dos lados acentuando en ocasiones el paso de uno de los lados al otro, esto es, la conversión de la vida falsa y decadente a la vida verdadera y seria. Acentúo esto porque me parece que el modelo de la conversión parece jugar un papel también fundamental en el pensamiento de todo el primer Heidegger, en la medida en que su filosofía de esos años tematiza siempre la posibilidad de una radical transformación en el modo de vida. En cuarto y último lugar quisiera hacer expreso que en dicho modelo $-\mathrm{y}$ en general en el marco valorativo desde el que Heidegger entiende la misión de su vida y su propio trabajo- está implicado también un programa político fuertemente dualista y conservador. Dicho programa puede apreciarse con toda claridad en estos primeros escritos, pero es plausible preguntarse si no se mantiene en los años que siguen $^{28}$. Desarrollar el análisis de todas estas continuidades y poner a prueba esta hipótesis de lectura deberá ser tarea para futuros trabajos.

\section{Referencias bibliográficas}

Casper, B. (1980): "Martin Heidegger und die theologische Fakultät Freiburg 1909-1923”, Freiburger Diözesan-Archiv 100, pp. 534-541.

De Lara, F. (2014): "El gesto político de las filosofías de Heidegger. Contribución a un debate actual", Veritas, 31, pp. 73-86.

De Lara, F. (2016): “¿Fenomenología de lo concreto? Crítica fenomenológico-política del programa filosófico de Heidegger en 1919/20", Trans/form/açao, vol. 39, n. 1, pp. 37-56.

Förster, Fr. W. (1911): "Nochmals Autorität und Freiheit", Zeitschrift für Philosophie und Pädagogik, 18, pp. 272-274.

Förster, Fr. W. (1920): Das Kulturproblem der Kirche, Kempten/München/Koblenz, Verlag der Jos. Kösel'schen Buchhandlung.

Fischer, M. (2013): Religiöse Erfahrung in der Phänomenologie des frühen Heideggers, Göttingen, Vandenhoeck and Ruprecht.

Habermas, J. (1987): Teoría de la acción comunicativa I, Madrid, Taurus.

Habermas, J. (1989a): El discurso filosófico de la modernidad, Madrid, Taurus.

Habermas, J. (1989b): Identidades nacionales y posnacionales, Madrid, Tecnos.

Heidegger, M. (GA 1): Frühe Schriften, Frankfurt a. M., Klostermann, 1978.

Heidegger, M. (GA 13): Aus der Erfahrung des Denkens 1910-1976, Frankfurt a. M., Klostermann, 1983.

Heidegger, M. (GA 14): Zur Sache des Denkens, Frankfurt a. M., Klostermann, 2007.

Heidegger, M. (GA 16): Reden und andere Zeugnisse eines Lebensweges, Frankfurt a. M., Klostermann, 2000.

Heidegger, M. (GA 62): Phänomenologische Interpretationen ausgewählten Abhandlungen des Aristoteles zur Ontologie und Logik. Mit dem Anhang: Phänomenologische Interpretationen zu Aristoteles (Anzeige der hermeneutischen Situation. Frankfurt a. M.: Klostermann, 2005.

Heidegger-Jahrbuch I: Denker, A., Zaborowski, H. y Gander, H.-H. (eds.), Heidegger und die Anfänge seines Denkens, Freiburg/München, Alber, 2004.

28 Para un análisis del fondo político de los primeros cursos friburgueses de Heidegger, puede verse De Lara (2014) y (2016). 
Klimke, Fr. (1910): Die Hauptprobleme der Weltanschauung, Kempten, Verlag Kösel.

Lukács, G. (1962): Die Zerstörung der Vernunft, Georg Lukács Werke, vol. 9, Darmstadt/ Neuwied, Luchterhand.

Ott, Hugo (1986): “Der Habilitant Martin Heidegger und das von Schaezler'sche Stipendium. Ein Beitrag zur Wissenschaftsförderung der katholischen Kirche", Freiburger Diözesanarchiv, 106 (1986), pp. 141-160.

Ott, Hugo (1988): Martin Heidegger. Unterwegs zu seiner Biographie, Frankfurt a. M./ New York, Campus.

Ott, Hugo (2004): "Martin Heidegger und seine Beziehungen zur Görres-Gesellschaft zur Pflege der Wissenschaft im katholischen Deutschland", en Heidegger-Jahrbuch I, pp. 197-200.

Ott, Hugo (2005): "Martin Heidegger und seine Beziehungen zur Görres-Gesellschaft", Historisches Jahrbuch, 125, pp. 169-173.

Schaber, J. (2007): "Heidegger frühes Bemühen um eine 'Flüssigmachung der Scholastik' und seine Zuwendung zu Johannes Duns Scotus", en Fischer, N. y Von Hermann, F. W. (eds.), Heidegger und die christliche Tradition, Hamburg, Meiner.

Schmidt, I. (2005): Von Leben zum Sein. Der frühe Martin Heidegger und die Lebensphilosophie, Würzburg, Königshausen \& Neumann.

Tilitzki, Ch. (2002): Die deutsche Universitätsphilosophie in der Weimarer Republik und im Dritten Reich. Teil 1, Berlin, Akademie Verlag.

Vonberg, M. (2003): "Der Messkircher Zeitigungskrieg. Oberbadischer Grenzbote und Heuberger Volksblatt im liberal-ultramontanen Streit", en Weber, E. (ed.), Renitenz und Genie. Messkirch und der badische Seekreis zwischen 1848/49 und dem Kulturkampf, Konstanz, Gesellschaft Oberschwaben.

Wolfe, J. (2013): Heidegger's Schatology. Theological Horizons in Martin Heidegger's Early Work, Oxford, Oxford University Press.

Wolfe, J. (2014): Heidegger and Theology, London/New Delhi/New York/Sydney, Bloomsbury.

Xolocotzi, A. (2009): Facetas heideggerianas, Puebla, Los libros de Homero. 